J. Lake Sci. (湖泊科学), 2011, 23(1): 104-111

http: //www.jlakes.org. E-mail: jlakes@niglas.ac.cn

(c) 2011 by Journal of Lake Sciences

\title{
区域河川径流量时空变异特征及成因分析一一广东省为例 ${ }^{*}$
}

涂新军 $^{1,2}$, 陈晓宏 ${ }^{1,2}, 弓^{\circ}$ 强 $^{1,2}$

( 1 : 中山大学水资源与环境研究中心,广州 510275 )

(2: 华南地区水循环与水安全广东省普通高校重点实验室,广州 510275$)$

\begin{abstract}
摘 要: 运用最大似然比和西沃兹信息标准的变点识别方法,对广东省主要江河 1956-1999 年的年径流量、汛期径流 量、枯水期径流量和最小月径流量的年序列, 进行均值变点和方差变点识别, 得出径流量特征值存在变点的序列类型、时 间位置、空间分布及时序变点前后的特征值变化状况,结合广东省降雨量序列变点识别、水利工程设施建设等气候和人 类活动影响因素的分析, 以揭示广东省河川径流量时空变异特征及主要成因. 结果表明:广东省河川年径流量和汛期径 流量序列的一致性较好, 而枯水期径流量和最小月径流量序列的特征值变点具有普遍性, 年均值明显增加, 年际离散程 度增大. 枯水期径流量序列均值变点的典型时间位置为 1973 年和 $1980-1981$ 年, 分布于西江支流贺江、东江、粤东沿海 螺河, 由水库等蓄水工程的径流调节作用而形成; 方差变点的典型时间位置为 1981 年, 主要分布于北江、韩江、粤西鉴江、 珠江三角洲的增江及网河区顶部干流水道, 与特丰年 1982 年的枯水期大量降水有关. 最小月径流序列主要为均值变点, 不同河流的变点时间位置有较大差异,但多集中在 $1972-1973$ 年, 分布于西江支流、东江、韩江及粤东沿海河流、珠江三 角洲的增江. 珠江三角洲顶部的北江干流水道的径流量变异尤其典型, 四种径流量序列均存在均值变点和方差变点, 典 型时间位置为 $1980-1981$ 年和 $1992-1993$ 年, 是由网河区剧烈的人类活动改变了河道分流比所导致.
\end{abstract}

关键词: 径流量;年序列;特征值变异;成因分析;广东省

\section{Spatial-temporal variability patterns of regional runoffs series and their root cause analy- sis, Guangdong Province}

TU Xinjun ${ }^{1,2}$, CHEN Xiaohong ${ }^{1,2} \&$ ZHANG Qiang ${ }^{1,2}$

(1:Center of Water Resources and Environment Research, Sun Yat-sen University, Guangzhou 510275, P. R. China)

(2:Key Laboratory of Water Cycle and Water Security in Southern China of Guangdong High Education Institute, Guangzhou 510275, P. R. China)

\begin{abstract}
Based on the change-point theory and methods, the likelihood ratio method testing in the mean and the Schwarz Information Criterion testing in the variance, change points of time series of the river runoff such as the full year runoff, the flood season runoff, the dry season runoff, and the least monthly runoff were recognized for main gauge stations of Guangdong Province from 1956 to 1999. Spatial-temporal location of these tested change points were described in detail, key features of the characteristics variability of time series of the river runoff were concluded on the whole, and furthermore root causes were illuminated for those change points of runoff time series in terms of the mean and the variance. In general, it showed that change point was widely tested in the existence of the dry season runoff and of the least monthly runoff, which the annual value increased significantly and fluctuated remarkably after the change-point time, otherwise of the full year runoff and of the flood season runoff. Furthermore, the change-point location in the mean of the dry season runoff obviously occurred to 1973 and 1980 - 1981 in the Hejiang River of the Xijiang Basin, the Dongjiang River, Luohe River of Eastern Guangdong coast mainly due to reservoirs adjustment, and the changepoint location in the variance of the dry season runoff to 1981 in the Beijiang River, the Hanjiang River, Jianjiang River of the
\end{abstract}

* 国家自然科学基金重点项目(50839005)、教育部人文社会科学研究青年基金项目 (09YJC910010)、中山大学青年 教师科研启动基金项目 (2008-37000-1131296)、广东省博士后启动基金项目(2009-37000-4203384) 和中山大 学青年教师重点培育项目 $(2009-37000-1132381)$ 联合资助. 2010-05-10 收稿; 2010-07-05 收修改稿. 涂新 军,男,1972 年生,博士, 讲师;E-mail: eestxj@ mail. sysu. edu. cn. 
Western Guangdong coast, Zengjiang River and the top water channel of the Pearl River Delta, mainly by the reason of the precipitation of the dry season in large quantity in 1982. However, it occurred to $1972-1973$ in spite of different change-point temporal location in the mean of the least monthly runoff, widely in Xijiang River and its streams, Dongjiang River, Hanjiang River, Zengjiang River, and rivers of Eastern Guangdong coast. In particular, change-point in the mean and in the variance were tested in the existence of these four kinds of annual series in the top Beijiang channel of the Pearl River Delta due to change of the split flow ratio on the channel net under the intensely human activities.

Keywords: Runoff; annual series; characteristics variability; root cause analysis; Guangdong Province

随着区域社会经济的快速发展, 用水量急剧上升, 水资源成为区域发展和地区安全的战略性资源. 在中 国,气候变化和人类活动影响下的区域河川径流量变化趋势的研究越来越受到关注 ${ }^{[-3]}$, 认为我国北方河流 的年径流量下降趋势明显 ${ }^{[4]}$. 作为中国改革开放的前沿地区广东省, 地处华南湿润区, 河网水系发达, 地表 水资源量丰富, 但在人口激增、工农业产值高速增长、城镇化快速推进、土地利用不断调整、水利工程建设、 河道条件改变等剧烈人类活动和全球气候变化的影响下, 部分河流的水文要素时间特征也发生了变化 ${ }^{[5-9]}$, 甚至枯水期径流量序列表现出明显的变异特征 ${ }^{[10-11]}$, 导致部分城市存在季节性缺水问题 ${ }^{[12]}$. 而无论是水利 工程设计, 还是水资源评价规划, 在构建河川径流量年序列分布模型时, 都要求进行变异性识别及一致性 修订.

目前已有的时间序列变异性识别方法大体可分为三类 ${ }^{[11]}$ : 一是已知该序列的随机分布模型, 通过构建 检验统计量识别参数变点; 二是已知该序列是随机分布的非参数识别方法; 三是不考虑序列是否随机分布 的变点识别方法. 本文的研究目标是通过识别时序分布模型的均值变点和方差变点, 以揭示广东省河川径 流量的时空变异特征, 并进行成因分析, 因此采用属于第一类的随机分布模型参数识别法: 最大似然比法和 西沃兹信息标准法.

\section{1 资料与研究方法}

综合考虑资料序列的完整性和流域代表性, 本文研究选取了 25 个水文站, 基本覆盖了珠江流域在广东 省境内的水资源二级分区和主要河流 (图 1). 用 $1956-1999$ 年 (水文年) 的逐月径流量资料, 构建径流量的 年序列: 全年径流量序列 $R_{\mathrm{y}}\left(4\right.$ 月至翌年 3 月)、汗期径流量序列 $R_{\mathrm{f}}\left(4-10\right.$ 月)、枯水期径流量序列 $R_{\mathrm{Lf}}(11$ 月 至翌年 3 月) 和全年最小月径流量序列 $R_{\text {min }}$. 在成因分析中, 选取了广东省境内 257 个雨量站 (图 1) 1956 -

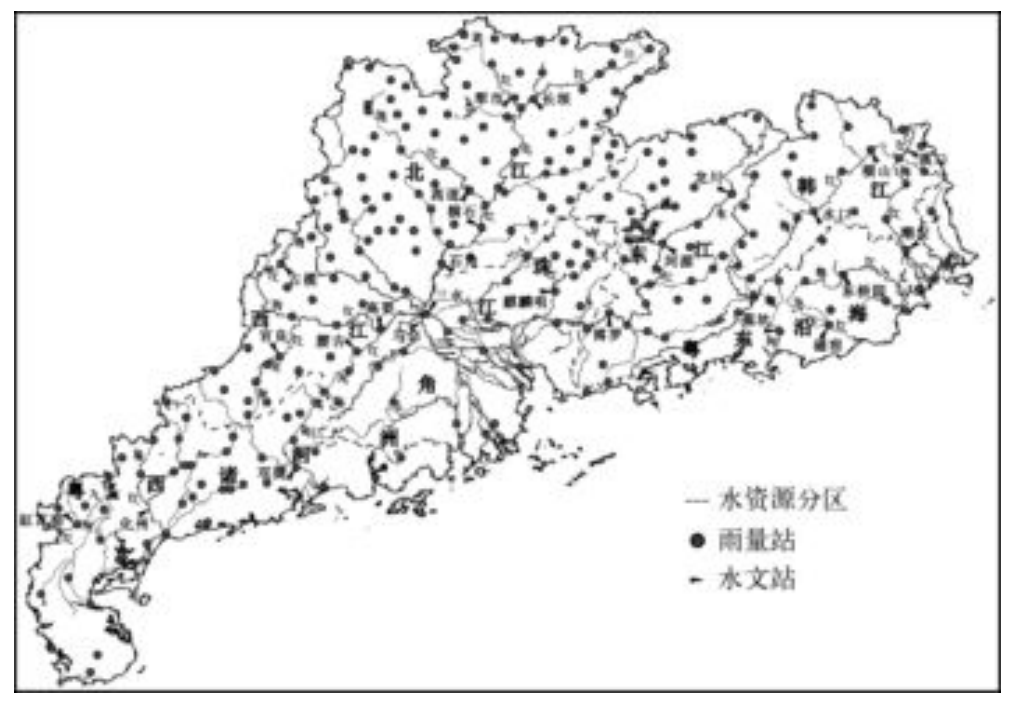

图 1 广东省主要河流水系及站点分布

Fig. 1 Sketch of main rivers and gauge stations in Guangdong Province 
1999 年 (水文年) 逐月降水量资料, 构建了与径流序列相对应的降水量年序列 $P_{\mathrm{y}} 、 P_{\mathrm{f}} 、 P_{\mathrm{Lf}}$ 和 $P_{\mathrm{m} \text { in }}$. 径流量和降 水量数据来源于 2004 年《广东省水资源综合规划》中的整编成果, 大中型水库特性数据还参考了 2004 年《珠 江水资源综合规划》中的整编成果, 东江三大水库的人流量和出流量数据来自各水库管理单位提供的整编 资料.

最大似然比法 ${ }^{[13]}$ 和西沃兹信息标准法 ${ }^{[10]}$ 均属于随机分布模型的参数识别法, 前提假设是时间序列为正 态分布随机变量, 前者用于识别均值变点, 后者用于识别方差变点, 其已在气象水文要素的时序变点识别中得 到应用. 本文采用这两种方法对广东省主要河流的四种径流量序列进行变异性识别,结果见图 2 和表 1.
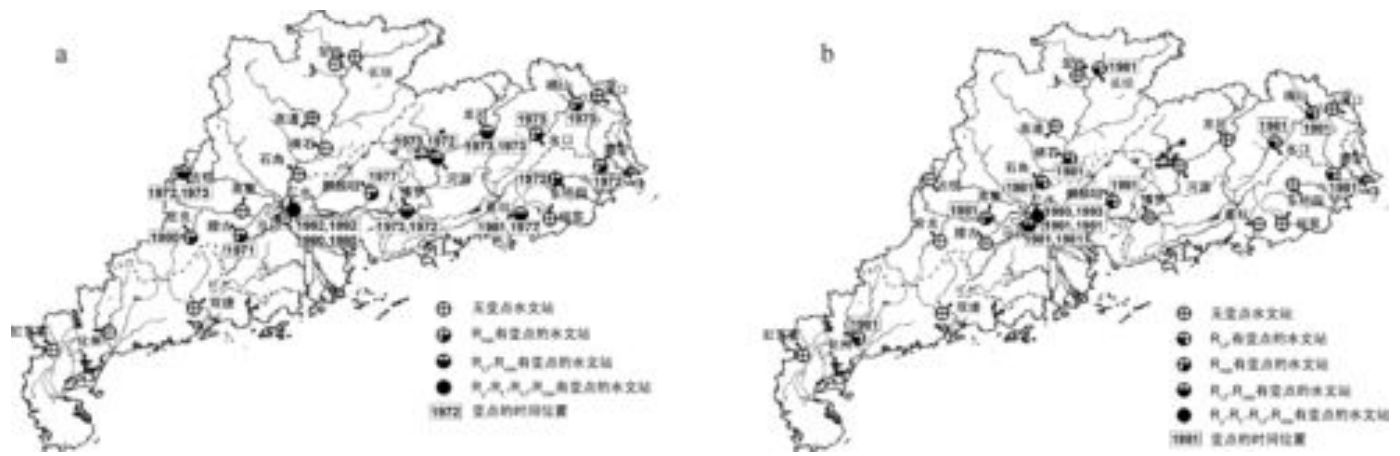

图 2 广东省河川径流量序列变点的时空分布 ( ( a ) 为均值变点, (b) 为方差变点)

Fig. 2 Spatial-temporal patterns of change points of runoff series in terms of mean value (a) and variance (b)

表 1 广东省河川径流量时序变点识别结果和特征值变化情况

Tab. 1 Time location of the change-point and characteristics comparison runoff series in Guangdong Province

\begin{tabular}{|c|c|c|c|c|c|c|c|c|c|c|c|c|c|}
\hline \multirow{2}{*}{$\begin{array}{c}\text { 径流量 } \\
\text { 序列 }\end{array}$} & \multicolumn{2}{|c|}{ 径流站 } & \multicolumn{2}{|c|}{ 均值 } & \multicolumn{2}{|c|}{ 变差系数 } & \multirow{2}{*}{$\begin{array}{c}\text { 径流量 } \\
\text { 序列 }\end{array}$} & \multicolumn{2}{|c|}{ 径流站 } & \multicolumn{2}{|c|}{ 均值 } & \multicolumn{2}{|c|}{ 变差系数 } \\
\hline & 序号 & 名称 & $\begin{array}{l}\text { 变点 } \\
\text { 位置 }\end{array}$ & $\begin{array}{l}\text { 变点后 } \\
\text { /变点前 }\end{array}$ & $\begin{array}{l}\text { 变点 } \\
\text { 位置 }\end{array}$ & $\begin{array}{l}\text { 变点后 } \\
\text { /变点前 }\end{array}$ & & 序号 & 名称 & $\begin{array}{l}\text { 变点 } \\
\text { 位置 }\end{array}$ & $\begin{array}{l}\text { 变点后 } \\
\text { /变点前 }\end{array}$ & $\begin{array}{l}\text { 变点 } \\
\text { 位置 }\end{array}$ & $\begin{array}{l}\text { 变点后 } \\
\text { /变点前 }\end{array}$ \\
\hline$R_{\mathrm{y}}$ & 24 & 三水 & 1992 & 1.86 & 1993 & 0.74 & $R_{\mathrm{f}}$ & 24 & 三水 & 1992 & 1.79 & 1993 & 0.65 \\
\hline \multirow{15}{*}{$R_{\mathrm{Lf}}$} & 2 & 古榄 & 1980 & 1.56 & & & \multirow{15}{*}{$R_{\min }$} & 1 & 高要 & & & \multirow[t]{13}{*}{1981} & \multirow[t]{13}{*}{2.13} \\
\hline & 6 & 长坝 & & & 1981 & 1.79 & & 2 & 古榄 & 1992 & 2.12 & & \\
\hline & 8 & 横石 & & & 1981 & 1.84 & & 3 & 官良 & 1980 & 1.39 & & \\
\hline & 9 & 石角 & & & 1981 & 1.95 & & 4 & 腰古 & 1971 & 1.64 & & \\
\hline & 10 & 龙川 & 1973 & 1.76 & & & & 10 & 龙川 & 1973 & 1.75 & & \\
\hline & 11 & 河源 & 1973 & 1.66 & & & & 11 & 河源 & 1972 & 1.78 & & \\
\hline & 12 & 博罗 & 1973 & 1.54 & & & & 12 & 博罗 & 1972 & 1.63 & & \\
\hline & 13 & 横山 & & & 1981 & 1.92 & & 13 & 横山 & 1973 & 1.51 & & \\
\hline & 14 & 水口 & & & 1981 & 1.88 & & 14 & 水口 & 1973 & 1.63 & & \\
\hline & 16 & 潮安 & & & 1981 & 1.96 & & 16 & 潮安 & 1972 & 1.38 & & \\
\hline & 18 & 蕉坑 & 1981 & 1.61 & & & & 18 & 蕉坑 & 1977 & 1.58 & & \\
\hline & 21 & 化州 & & & 1981 & 1.97 & & 19 & 东桥园 & 1972 & 1.62 & & \\
\hline & 23 & 麒麟咀 & & & 1981 & 2.41 & & 20 & 麒麟咀 & 1977 & 1.57 & & \\
\hline & 24 & 三水 & 1980 & 2.05 & 1981 & 1.78 & & 24 & 三水 & 1980 & 2.81 & 1981 & 1.35 \\
\hline & 25 & 马口 & & & 1981 & 2.31 & & 25 & 马口 & & & 1981 & 3.17 \\
\hline
\end{tabular}

\section{2 时空变异特征}

\section{1 变点分布}

西江干流及支流为 1971 年 (腰古) 、1980 年(古榄、腰古)、1981 年 (高要) 和 1992 年 (古榄), 北江干流 
为 1981 年 (长坝、横石、石角), 东江干流为 $1972-1973$ 年(龙川、河源、博罗), 韩江干流为 $1972-1973$ 年和 1981 年 (横山、水口、潮安), 粤东沿海榕江为 1972 年 (东桥园)、螺河为 1977 年和 1981 年 (蕉坑), 粤西鉴江 为 1981 年 (化州), 珠江三角洲增江为 1977 年和 1981 年(麒麟咀), 三角洲网河区顶部为 $1980-1981$ 年 (三 水、马口) 和 $1992-1993$ 年 (三水).

$R_{\mathrm{y}}$ 和 $R_{\mathrm{f}}$ 仅有珠江三角洲网河区顶部北江干流水道 (三水) 存在变点, 时间位置为 1992 年 (均值变点) 和 1993 年 (方差变点), 表明除个别站点外,广东省河川径流的 $R_{\mathrm{y}}$ 和 $R_{\mathrm{f}}$ 基本不存在变点. $R_{\mathrm{Lf}}$ 和 $R_{\mathrm{min}}$ 存在变点的 测站较多, 占测站总数的 $60 \%$, 表明广东河流的枯水期和最小月径流序列存在时序变点的普遍性. 径流序列 变点主要分布在 $1972-1973$ 年(多为均值变点) 和 1981 年(多为方差变点), 表明广东省河川径流在这两个 时间段存在枯水时序变点的典型性.

\section{2 特征值变化}

2.2. 均值变化 变点后子序列的均值与变点前相比, 各径流序列的均值均为增加. 西江支流的枯水期径 流量增加了 $56 \%$ (贺江), 最小月径流量增加了 1.12 倍(贺江)、39\% (罗定江) 和 64\% (新兴江) ; 东江干 流的枯水期径流量增加了 $76 \%$ (东江上游)、66\% (东江中游)、54\% (东江下游), 最小月径流量增加了 $75 \%$ (东江上游)、 $78 \%$ (东江中游) 、63\% (东江下游) ; 韩江干流及支流的最小月径流量增加了 $51 \%-63 \%$ (梅江)、38\% (韩江下游) ; 粤东沿海河流的枯水期径流量增加了 $61 \%$ (螺河), 最小月径流量增加了 $58 \%$ (螺河)、62\% (榕江); 珠江三角洲的河流最小月径流量增加了 57\% (增江), 网河区顶部的北江干流水道 (三水) 年径流量和汛期径流量分别增 了 $86 \%$ 和 79\%, 枯水期径流量和最小月径流量分别增加了 1.05 倍和 1.81 倍.

2.2.2 离散程度变化 变点后子序列的变差系数与变点前相比,除珠江三角洲网河区顶部的北江干流水道 (三水) 年径流量和汛期径流量的分别减少 $26 \%$ 和 $35 \%$ 之外, 枯水径流序列的离散程度均增大. 枯水期径流 量方面，北江干流、韩江干流及支流、粤西河流、珠江三角洲河流 (水道) 分别增大了 $79 \%$ (北江上游)、 $84 \%$ ( 北江中游)、 $95 \%$ ( 北江下游)、88\%-92\% (梅江)、96\% (韩江下游)、97\% (鉴江)、1.41 倍( 增江)、78\% (三 水, 北江干流水道) 和 1.31 倍 (马口, 西江干流水道); 最小月径流量方面, 西江和珠江三角洲顶部水道分别 增大了 1.13 倍(高要, 西江干流)、35\% (三水, 北江干流水道)、2.17 倍 (马口, 西江干流水道).

\section{3 成因分析}

河川径流量时空格局发生变化, 主要受气候变化和下垫面改变两方面的影响. 降水、气温等气候因子变 化, 影响区域水循环过程, 可能会导致河川径流量的增减; 农业生产、城市化及水利工程建设等下垫面及河 道条件的改变,影响产汇流的形成过程,会使河川径流量在时空上重新分配.

(1) 广东省河川径流量的补给来自于大气降水, 同样利用最大似然比法和西沃兹信息标准法对 257 个 雨量站的 $P_{y} 、 P_{\mathrm{f}} 、 P_{\mathrm{Lf}} 、 P_{\min }$ 进行时序变点的识别 (图 3). 结果显示, $P_{\mathrm{y}} 、 P_{\mathrm{f}} 、 P_{\mathrm{Lf}} 、 P_{\min }$ 出现均值变点和 $P_{\mathrm{y}} 、 P_{\mathrm{f}}$ 出现 方差变点的站点数较少, 分别占总站点数的 $6.2 \% 、 4.3 \% 、 1.6 \% 、 0.0 \%, 1.9 \% 、 2.7 \% ; P_{\mathrm{L}} 、 P_{\min }$ 出现方差变点 的站点数较多, 比例分别达到 $18.7 \% 、 19.5 \%$. 表明广东省大多数地区 $P_{\mathrm{y}} 、 P_{\mathrm{f}}$ 基本都不存在变点, 具有较好的 一致性,这与河川径流的 $R_{\mathrm{y}} 、 R_{\mathrm{f}}$ 均不存在时序变点的结论基本一致. $P_{\mathrm{If}} P_{\min }$ 的方差变点具有一定的普遍性, 时序变点主要分布于东江、韩江和西江, 其中枯水期降水量典型时间位置为 1981 年 (图 3G), 与 $R_{\mathrm{Lf}}$ 变点的时 间位置基本一致.

(2) 对存在方差变点的 8 个测站, 分析枯水期降水量-径流深的年际变化, 发现两者之间同样存在高度 相关性, 且均在 1982 年出现降水和径流的最大值, 与多年平均的枯水期降水量和径流深相比, 分别达到了 $2.47-3.67$ 倍和 3.36-4.37 倍 (图 4). 同样利用西沃兹信息标准法, 计算各站枯水期降水量序列的最大西 沃兹信息 $S_{\text {max }}$ 和去除最大值的枯水期径流量序列的 $S_{\text {max }}$ (图 5). 结果显示韩江 (横山、水口、潮安) 和增江 (麒 麟咀) 的枯水期降水量同样存在方差变点, 而 8 个测站若忽略径流量最大值的枯水期径流量均不存在变点, 表明广东省主要河流枯水期径流量的方差变点 (1981 年) 与 1982 年枯水期降水量过大有关, 韩江和增江尤 为典型. 

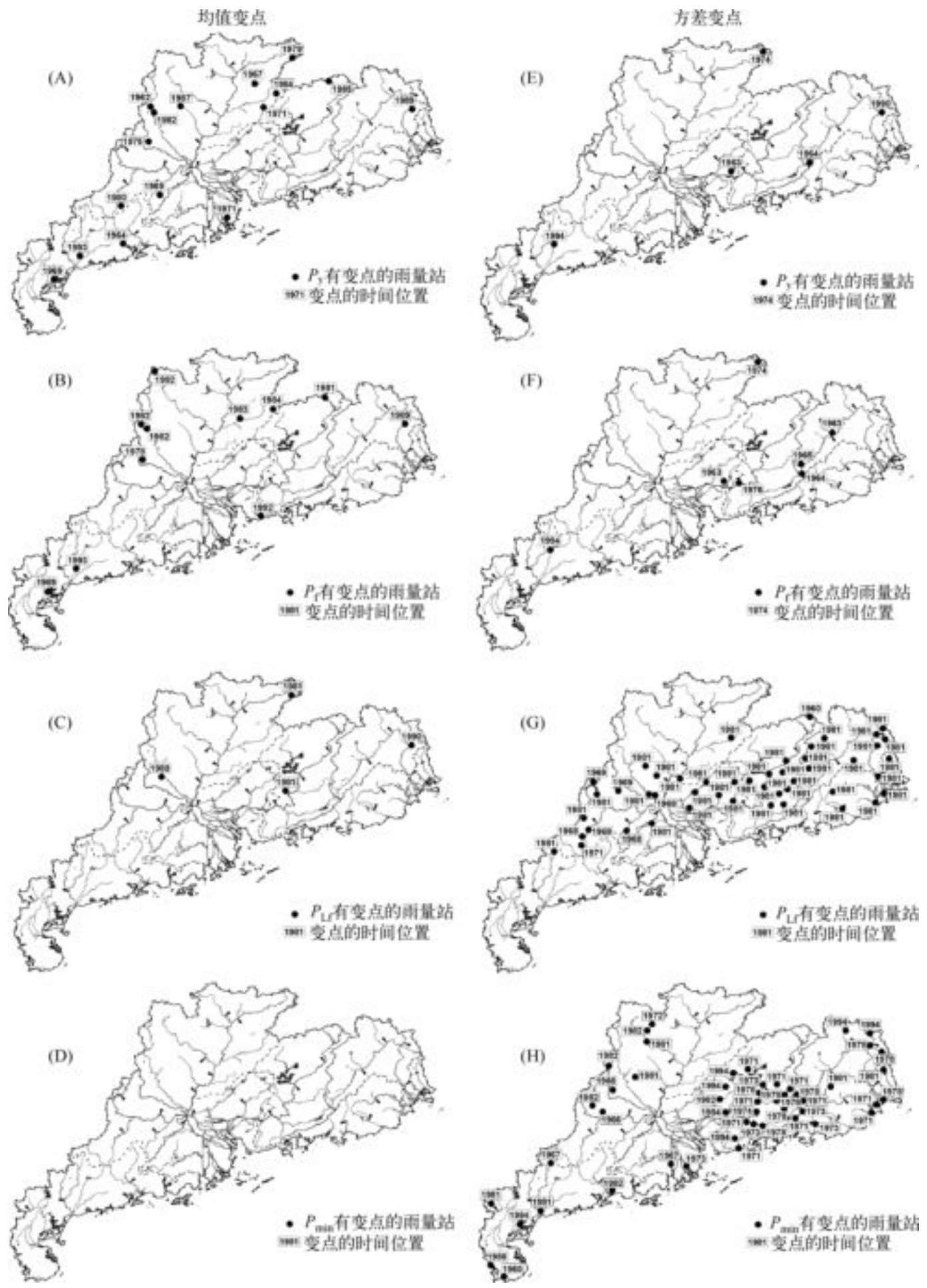

图 3 广东省降水量序列特征值变点的时空分布

Fig. 3 Spatial-temporal patterns of change points of precipitation series 


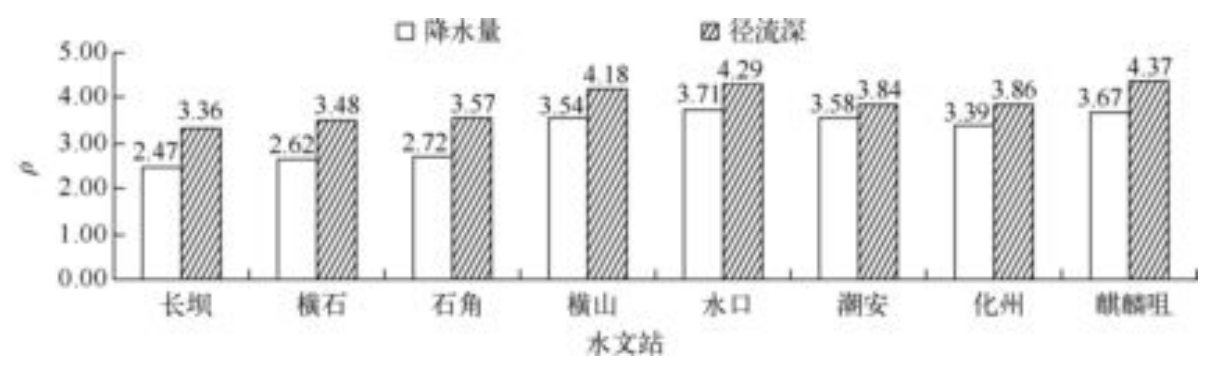

图 4 存在方差变点的水文站特丰年(1982 年)降水-径流的 $\rho$ 分布

( $\rho$ 为 1982 年枯水期降水量或径流量与多年平均的枯水期降水量或径流量之比)

Fig. $4 \rho$, the ratio of precipitation and runoff in the dry period in 1982 being larger than the rest years for stations existing variance change point

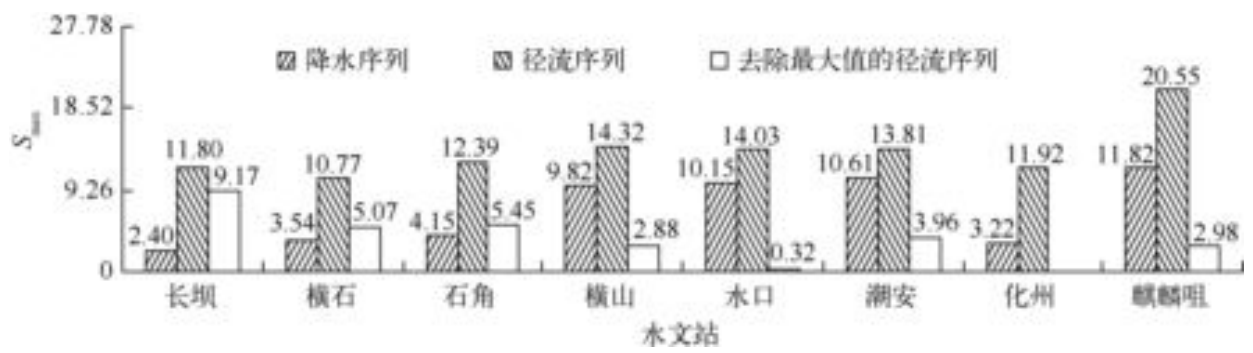

图 5 存在方差变点的水文站枯水期降水-径流方差变点识别的 $S_{\text {max }}$ 对比

Fig. $5 S_{\max }$ comparison of precipitation, runoff and its series of removing largest values in the dry period for stations existing variance change point

(3) 20 世纪 50 年代起,中国开始了大量修筑水库、塘坝等蓄水工程. 截至 2000 年底,本文研究的水文 站集水区内建有中型以上水库 (总库容 $>10^{7} \mathrm{~m}^{3}$ ) 392 座, 调节库容累计约 $402.4 \times 10^{8} \mathrm{~m}^{3}$, 其中广东省境内 175 座, 调节库容累计约 $289.5 \times 10^{8} \mathrm{~m}^{3}$. 水库的季调节、年调节和多年调节作用将改变河川径流量年内、年际 分配过程,尤其对枯水径流的年序列特征影响较大.计算中型以上水库径流调节系数 $\beta$ (图 6), 反映了广东 省主要水文测站集水区的水库对径流量调节能力的大小, 东江流域尤其突出, 上、中、下游测站 (龙川站、河 源站、博罗站) 集水区水库的径流调节系数分别达到了 $0.20 、 0.53 、 0.36$. 以东江流域为例,截至 2000 年底, 东江流域控制站 (博罗站) 集水区建有中型以上水库 36 座, 兴利库容约 $86.3 \times 10^{8} \mathrm{~m}^{3}$, 其中具有多年调节能 力的大 $\left(\right.$ 一) 型水库 (总库容 $\left.>10^{9} \mathrm{~m}^{3}\right) 3$ 座, 在上、中、下游各有 1 座 (枫树坝水库、新丰江水库、白盆珠水库),

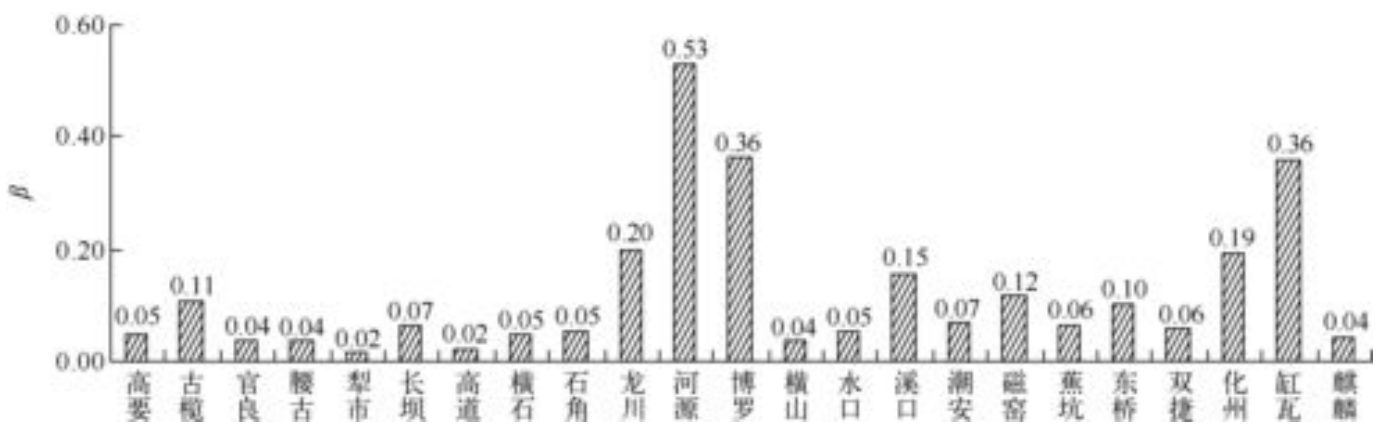

图 6 广东省水文测站集水区水库调节系数 $\beta$ 的分布

( $\beta$ 为水库调节系数, $\beta=\sum V / R, \sum V$ 为测站集水区的调节库容累计量, $R$ 为测站多年平均年径流量)

Fig. 6 Regulation coefficients, $\beta$, of the water reservoirs of stations in Guangdong Province, representing the regulating capacity or regulating potential of water reservoirs for the streamflow changes 
投人运行分别始于 1974 年、1961 年、1986 年, 可调节库容累计 $81.3 \times 10^{8} \mathrm{~m}^{3}$, 三大水库对博罗站径流量的调 节系数 0.34. 基于三大水库人流和出流的月径流序列, 对博罗站的月径流序列进行还原 (图 7), 并利用最大 似然比法进行均值变点的识别, 对比分析枯水期径流量序列还原前后的似然比统计量变化 (图 8), 很显然, 实测序列在 $1967-1974$ 年的似然比统计量大于检验值(3.04), 存在时序变点, 而还原后则满足均值变点的 $H_{0}$ 假设, 不存在时序变点, 表明三大水库的调节作用是引起东江枯水期径流量序列特征值变异的主要原因.

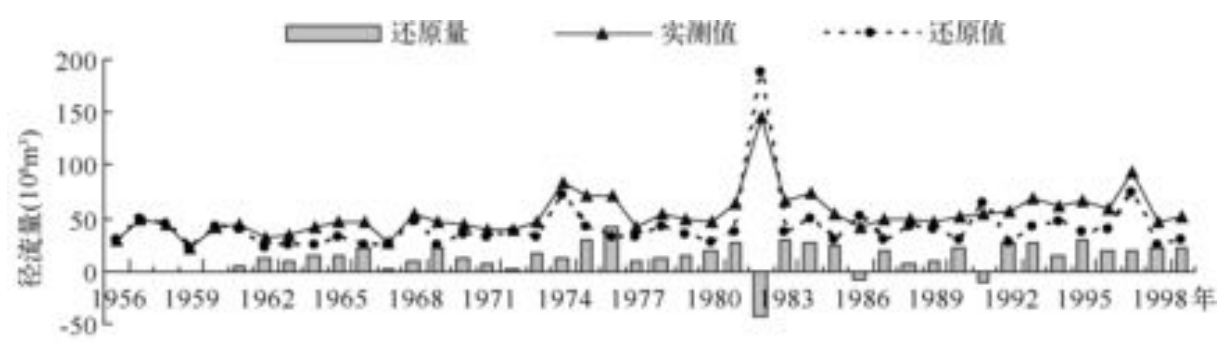

图 7 东江博罗站枯水期径流量年变化

Fig. 7 Annual change of the observed, reconstructed runoff series and the difference between these two runoff series in the dry period of Boluo station in the Dongjiang River

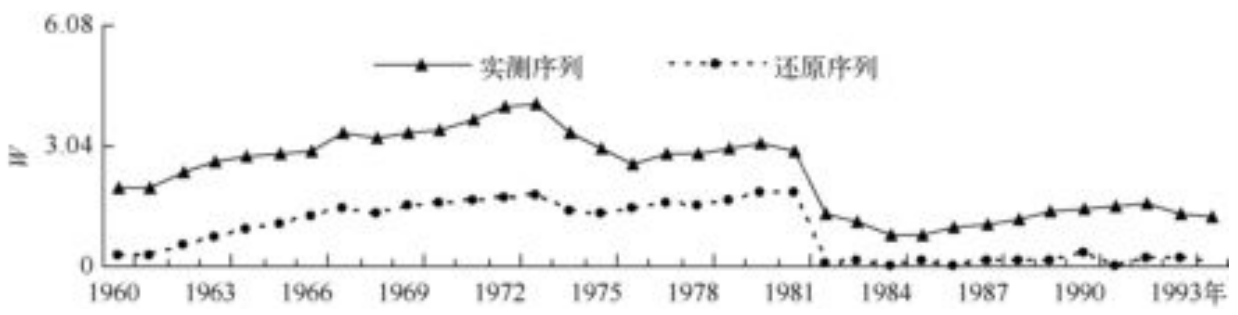

图 8 东江博罗站枯水期径流量序列均值变点的似然比统计量变化

Fig. $8 \mathrm{~W}$, the likelihood ratio statistic change of the observed and reconstructed runoff series in the dry period of Boluo station in the Dongjiang River

(4) 珠江三角洲顶部的西江干流水道和北江干流水道 (三水)之间, 有思贤深水道 (均在马口站和三水 站的上游) 连接, 水流在汛期因西江来水大, 为西江干流水道流人北江干流水道, 而在枯水期则因北江河床 高于西江, 水流相反. 但 20 世纪 90 年代后, 由于珠江三角洲网河区河道大规模采砂、航道整治等人类活动导 致河床下切, 思贤浫枯水期水流也是由西江干流水道流人北江干流水道, 且马口站与三水站的汛期和枯水 期分流比均明显下降 ${ }^{[14]}$. 由于马口站的径流量较大, 三水站径流量较小, 分流比的变化对西江干流水道的径 流量序列特征影响较小, 但对北江干流水道的径流量序列特征影响显著, 这与三水站的年径流量序列和汛 期径流量序列均在 $1992-1993$ 年出现均值变点和方差变点的变异特征相吻合.

\section{4 结论}

(1) 总体上来说, 广东省河川年径流量和汛期径流量的序列一致性较好, 而枯水期径流量和最小月径 流量序列变点较为普遍, 年均值明显增加,年际离散程度增大, $1972-1973$ 年和 1981 年为变点的典型时间 位置.

（2）广东省河川径流量补给主要来自于大气降水, 河川径流的年径流量序列及汛期径流量序列基本不 存在变点, 与年降水量及汛期降水量序列一致性具有高度关联性; 枯水期径流量序列方差变点, 与特丰年 1982 年枯水期大量降水有关; 水库等蓄水工程的径流调节作用, 是枯水期径流量序列均值变点存在的主要 原因; 珠江三角洲顶部水道径流量变异, 是由于网河区剧烈人类活动改变了河道分流比所导致的.

(3) 由于大部分广东省河流的枯水期和最小月径流量的序列存在变点, 会影响到广东省水资源开发、 
利用和保护中径流量序列设计频率计算的可靠性,需要进行序列一致性修订或重构才能应用于工程设计 中. 对于引起河川径流量变异的影响因子定量化分解, 存在变点的径流序列如何进行一致性修订及重构等 问题,有待进一步的深人研究.

\section{5 参考文献}

[1 ] 张国胜,李 林,时兴合等. 黄河上游地区气候变化及其对黄河水资源的影响. 水科学进展, 2000,11(3): 277-283.

[2 ] 包为民,胡金虎. 黄河上游径流资源及其可能变化趋势分析. 水土保持通报,2000,20(2): 15-18.

[ 3 ] 王云璋, 康玲玲,王国庆. 近 50 年黄河上游降水变化及其对径流的影响. 人民黄河,2004,26(2):5-7.

[ 4 ] 张建云,章四龙,王金星等. 近 50 年来中国六大流域年际径流变化趋势研究. 水科学进展, 2007, 18 (2): 230-234.

[ 5 ] 陈晓宏,陈永勤. 珠江三角洲网河区水文与地貌特征变异及其成因分析. 地理学报,2002,57(4): 429-436.

[6] 李 艳,陈晓宏,王兆礼. 人类活动对北江流域径流系列变化的影响初探. 自然资源学报,2006,21 (6) : 910-915.

[ 7 ] 杨 涛,陈永勤,陈 喜等. 复杂环境下华南东江中上游流域筑坝导致的水文变异. 湖泊科学, 2009, 21 (1): 135-142.

[ 8 ] Chen YD, Zhang Qiang, Xu Chongyu et al. Change-point alterations of extreme water levels and underlying causes in the Pearl River Delta, China. River Research and Applications, 2009 ,25(9):1153-1168.

[ 9 ] Zhang Qiang, Xu Chongyu, Becker S et al. Trends and abrupt changes of precipitation maxima in the Pearl River basin, China. Atomospheric Science Letter, 2009, 10: 132-144.

[10］涂新军,陈晓宏. 基于西沃兹信息准则的水文时序方差变点识别. 水文,2008,165(3): 14-17.

[11] 涂新军,陈晓宏. 基于秩统计量枯水径流分布变点的非参数识别. 水利学报, 2009,40(5): 603-607.

[12］刘丙军,陈晓宏,张 灵等. 中国南方季节性缺少地区水资源合理配置研究. 水利学报, 2007,38(6) : 732-737.

[13] 杨喜寿,杨洪昌. 气候时间序列变点的推断. 大气科学, 1996,20(1): 47-53.

[14] 姚章民,王永勇,李爱鸣. 珠江三角洲主要河道水量分配比变化初步分析. 人民珠江, 2009,(2): 43-46. 